\title{
Harmonizing forest inventories and forest condition monitoring - the rise or the fall of harmonized forest condition monitoring in Europe?
}

\begin{abstract}
Ferretti $M$
Considerable attention was received by the proposed "harmonization" process between forest condition monitoring (FCM) and "traditional" national forest inventories (NFIs) networks. While some harmonization has been achieved and documented within the FCM at European level, it is not so for NFIs. Since the two systems may show remarkable differences also at country level, the extent to which a fully harmonized European-scale FCM-NFI system can be achieved is rather uncertain, if ever possible. In contrast, different harmonization perspectives may be considered at national level: (i) harmonization of assessment/measurement methods, (ii) functional integration of network while keeping them separate, and (iii) full integration of networks. Unfortunately while the cost-benefit balance of this harmonization processes was not clarified, actions were already undertaken that may lead to the disruption of the FCM data series initiated in the 1980 s. The conclusion of the process may be ironical: will the current effort in "harmonizing" NFIs and FCM results into the disruption of the European-wide longest and most harmonized time series of forest condition data?
\end{abstract}

Keywords: Networks, Time series, Harmonization, Integration, Forest

\section{Introduction}

Considerable attention was received by the proposed "harmonization" between largescale monitoring of forest condition and traditional national forest inventories currently being developed by the Life+ project FutMon (http://www.futmon.org/). The issue was discussed at an international meeting held in Firenze, Italy, on March 20, 2009 (http://www.aisf.it/futmon/20.htm). The reason is clear: while the subject is of general importance (e.g., Köhl et al. 2000, Olsen et al. 1999), it is particularly so for a project like FutMon, which aims at the Further Development and Implementation of an EUlevel Forest Monitoring System.

The large-scale monitoring of forest condition (hereafter referred to as FCM) started in Europe in the 1980s under the auspices of UN/ECE Convention on Long Range Trans-

TerraData environmetrics, v. P. A. Mattioli, I-53100 Siena (Italy)

\section{@) Marco Ferretti (ferretti@terradata.it)}

Received: Jul 23, 2009 - Accepted: Sep 26, 2009

Citation: Ferretti M, 2010. Harmonizing forest inventories and forest condition monitoring - the rise or the fall of harmonized forest condition monitoring in Europe? iForest 3: 1-4 [online: 2010-01-22] URL: http://www.sisef.it/iforest/show.php? id $=518$ boundary Air Pollution (with its ICP Forests) and of the European Union Regulation 3528/86 (Moffat et al. 2008). At that time, the alleged decline of forests in Europe was seen as a transboundary problem and a coordinated approach was advocated to obtain harmonized data and information (e.g., Innes 1993, Anonymous 1988, and subsequent reports of the UN/ECE and EU). For this reason, FCM was characterized since its early stages by an international perspective, promoted at both EU and UN/ECE level. Also because some conspicuous financial support (FCM in member states was sponsored by the EU at $50 \%$ over the period 1986-2005), this has resulted into an unprecedented effort to harmonize forest monitoring methods across Europe: defined sampling frequency (annual), density (nominal density: 1 plot every $256 \mathrm{~km}^{2}$ ) and attributes (defoliation, discolouration, damage causes) were suggested in order to obtain comparable and representative statistics at pan-European level; and as early as 1987 a first common Manual was agreed upon by the countries participating to the UN/ECE ICP Forests (Anonymous 1994). Since 1987 a series of co-ordinated annual surveys initiated and a time series of $10-20$ yrs is now available for tree condition over much of Europe (Lorenz et al. 2009). Alongside, a series of meetings, workshops and cross-calibration courses were undertaken at national and international level to promote the calibration and comparison of methods (Ferretti et al. 2009). Yet, some questions remain unsolved (Cozzi et al. 2002, Percy \& Ferretti 2004):

- sampling design in terms of sampling scheme, density and plot design (e.g., fixed area $v s$. fixed number of trees) are different among counties;

- revisions of the FCM network to account for changes in forest coverage are not harmonized across Europe;

- tree condition assessment criteria (reference standard, assessable crown, defoliation $v s$. crown transparency) are not harmonized and - in some Countries - have changed over time.

Although the above limitations may be so important to hamper the value of the data (e.g., spatial comparison: Innes et al. 1993, Ferretti 1997, Ferretti 2004), a continuous, not yet fully exploited, time series of data about thousands of trees and plots across Europe exists (see Lorenz et al. 2009, and references therein). While other long-term, large-scale forest monitoring programmes exist (e.g., Forest Health Monitoring in the US started in the 1990s), such a data series is perhaps the largest in geographical coverage, the longest in time and the most documented one available in Europe and - at this level spatial and time coverage - perhaps in the world. In addition, there are information and data (at international and often at national level) to document FCM data consistency across time and space (e.g., Cozzi et al. 2002, and references therein, Mues et al. 2005, Ferretti et al. 2009).

Unlike FCM, National Forest Inventories (NFIs) were traditionally designed to provide country-based estimates of different forest areas and timber, non-timber attributes. As such and because of historical, commercial, and environmental justification (Mc Roberts et al. 2009), sampling designs, sampling frequency, definitions, methods and attributes were largely different across Europe (e.g., Köhl et al. 2000). Despite the recent work carried out under the COST Action E43 (http://www.metla.fi/eu/cost/e43/), "prospects for standardizing inventories are minimal" (Mc Roberts et al. 2009), while "amoderate level of European-wide harmonization" was reported as possible (Winter et al. 2008), depending on the objectives,.

In general terms, NFI and FCM have similar features: they are typical sample surveys and their objective - loosely speaking - is to obtain reliable estimates of population parameter for the attribute(s) of concern, and to estimate time changes. Thus, harmonized FCM and NFI networks, or may be a single network of field plots supporting both NFI and FCM information needs, would offer considerable logical, logistical, technical, financial and information advantages, raising 
the value of FCM in Europe. As resulted from opinion collected in the reported meeting, these advantages were advocated to promote the harmonization process between FCM and NFI. Unfortunately, no formal cost-benefit analysis was presented to support the intuitive advantages reported above For this reason, and at this very stage, it is important to carefully consider the meaning, process and costs of this "harmonization": wrong decisions may result into the fall, rather than the raise, of harmonized FCM in Europe.

\section{Harmonization in theory and practice}

According to the on-line Webster's, "harmonization" is the process of establishment, recognition, and application of internationally recognized measures or standards. In my understanding, and in the present context, "harmonization" needs to consider three main subjects (attributes and assessment methods, plots and tree selection, network structure) and - according to the chosen subject - may have three practical meanings.

1. Harmonization of FCM and NFI attributes and relevant assessment/measurement methods. This implies adopting typical FCM attributes and assessment/measuremen methods within the set of the NFI ones (and/or the other way round). This not necessitates any change in network and plo design: networks may stay separated, plots may keep their own characteristics, but the adoption of consistent methods will led to harmonized datasets in terms of attributes. This is the slightest possible "harmonization" action to be undertaken;

2. Functional integration of FCM and NFI networks. Under this harmonization perspective, networks remain separated, but they will use not only the same attributes and methods (see above), but also the same plot design, which implies consistency in tree selection criteria. In this perspective, FCM plots may adopt the design used in the NFIs, while keeping the assessment also on trees that were previously considered. Assessment will be done on both FCM and NFI networks, although not necessarily with the same time frequency (see below). This implies some work to be done to adapt the plots, but - under the assumption of a common target population results can be used jointly to derive more precise and robust estimates.

3. Full integration of FCM and NFI networks (all-in-one). Under this perspective, original FCM plots will be ceased and FCM attributes will be measured only on NFI plots. The other way round (closing NFI plots in favour of FCM) is also possible, although less likely. A single, fully integrated and harmonized set of data will be obtained. However, if FCM plots are closed and moved to NFI ones, the FCM data series will be lost, at country level, and - as a consequence - at European level. Another perspective is the harmonization of the estimation process. It is worth noting that none of the above harmonization perspectives will solve the problem that NFIs network and plot designs differ across Europe, so it will be for FCM. Thus, harmonization will be possible only at the estimation stage (e.g., Mc Roberts et al. 2009).

\section{Harmonization processes}

The process by which "harmonization" can be achieved rests on the existing relationship between NFIs and FCM networks at national level. Some cases can be identified.

Case 1. FCM and NFI are already on the same network

This may have occurred because FCM was established on existing NFI networks (most frequent) (e.g., Austria, Switzerland) or the otherway round (e.g., Romania). In general, a subsample of NFI plots was used for FCM. In these cases networks are fully integrated, no assumption about nature of target populations is needed, and harmonization exists in facts at national level. Some further "harmonization" may be necessary due possible adaptation of survey methods in agreement to international procedure, but such a process can be traced and documented. The existing differences of NFIs and FCM across Europe will remain. Case 1 will be not discussed further here.

\section{Case 2. Countries with separate NFI} and FCM networks

This may have happened because:

- there was no NFI in the past, and FCM was created before NFI;

- the NFI and FCM were developed independently, as the agencies managing FCM and NFI were different and not communicating;

- countries with a former joint NFI-FCM network (Case 1) abandoned (for a variety of reasons) their original NFI for a newly designed one, thus having now two separate networks. For example Italy, where FCM was installed on a subsample of the $1^{\text {st }}$ NFI (see MAF-ISAFA 1985), and where the $2^{\text {nd }}$ NFI adopted a totally different design (Fattorini et al. 2006).

In every case the result is that today NFI and FCM are carried out on different networks. In these cases, harmonization can have each of the three meanings reported above.

\section{Possible scenarios under Case 2}

\section{Harmonization of methods}

Harmonization of methods implies that FCM and NFI will adopt similar protocols for assessment/measurements. This also mean common training, and Quality Assurance/Quality Control (e.g., Bussotti et al. 2009, Gasparini et al. 2009). With the simple harmonization of assessment/measurement methods, datasets will be harmonized in terms of attributes and measurements, but not necessarily they can be integrated to obtain a single population estimate. For example, when NFI uses fixed area plots and FCM uses plot with fixed number of trees, and/or when target populations differ. In addition, it may be the case that new procedures will be necessary to select sample trees within the NFI plots, thus implies additional work. However, as NFIs have in general a more relaxed time intensity (e.g., every 5 years $v$ s. annual surveys of FCM), costs will increase only slightly. The most important advantage of this harmonization will be the maintenance of existing data series, and, at the same time, supplementing the NFI dataset with new attributes. Disadvantages are limited, and relatively little work will be necessary.

\section{Functional integration of networks}

A further step in the harmonization process would be to keep the two networks (FCM and NFI), with the following adjustments:

- add FCM attributes and assessment methods to a comparable number of NFI plots (to be selected according to the country NFI design), and carry out the FCM measurements on (a sample of) trees at the selected NFI plots. Avoid permanent numbering on trees and annual visits on NFI plots in order to keep the plot as anonymous and undisturbed as possible. Rather, carry out FCM assessment on these plots at each NFI cycle (e.g., every 5 years);

- adopt the NFI plot design and attributes also for the existing FCM plots. At the same time keep also the former sample trees at the FCM plots. Do annual FCM on the "old" and the newly selected sample trees.

This will results in several advantages: the existing time series is maintained; comparison between the two dataset will be possible at defined time intervals; combined (and more precise) estimates may be possible at defined intervals. This latter possibility rests however on the very nature of the FCM network (its origin and target statistical population), and under the assumption that FCM and NFI samples concern the same statistical population. NFI plots will stay undisturbed. Disadvantage is a slight increase of costs (FCM plots adaptation at first year; some new attributes on NFIs at each inventory cycle). Differences of NFIs and FCM across Europe will remain.

Full integration of networks (all-in-one)

Regardless what network will be aban- 
doned, this process implies cutting a data series (or keep it on a very limited number of plots). The longer and the more consistent the data series, the higher the cost in terms of vanished investments and lost of data series Two cases may occur: FCM is moved to NFI or the other way round.

- FCM moved to NFI. Under this scenario, FCM attributes will be measured on NFI plots only. The advantage is often identified in "more representative" sample and the possibility for sound statistical estimates. However, at the above referred workshop, in most cases "representative" was intended to mean that the tree species composition of the NFI sample is more "updated" than the FCM one, and not to mean the statistical properties of the sample (e.g., elements of randomness in the selection, known and positive selection probability, independency). It is certainly true that FCM networks are getting biased: they were installed in 1980s and seldom updated; in addition, the "fixed-number-oftrees" plot concept implies the assessed trees remain the same across time, nearly ignoring ingrowth and suffering from a progressive ageing; further, tree selection a probabilistic sample (e.g., angle count) However, these drawbacks can be solved by simple actions: (i) shifting from the "fixed-number-of- trees" plot concept to the "fixed-area" plot, and by (ii) updating the coverage of the plots in order to account for changes in forest area. By the way action (i) was already largely done in the frame of the BioSorl project on the FCM plots (Working Group on Forest Biodiversity 2007). The most important disadvantage of the all-in-one solution is the loss of a 10-20 yrs time series. A further disadvantage is that FCM requires annual visits to the plots and this may result in disturbances that are not acceptable for the purposes of NFI. In any case, however, differences among countries will remain as a result of differences in NFIs.

- NFI moved to FCM. This is unlikely as in general NFI requirements cannot be attained by FCM networks, which are based (in general) on more relaxed sampling density and have - in general - trees with permanent numbering. However, it may occur when financial constrains require to have one single network and/or the FCM has the longest time series (e.g., Romania) In this case, FCM plots must fit NFI requirements and sampling density intensified.

A concrete example of shift from FCM to NFI was in Bavaria (Germany), were the shift was suggested to optimize existing networks: the FCM (installed in 1983, 4 x $4 \mathrm{~km}$ grid); the NFI (installed in 1987, on a different $4 \times 4 \mathrm{~km}$ grid, shifted by $200 \mathrm{~m}$ east and 200 north. The NFI was repeated in 2002); the first soil inventory (installed in 19861989 on a subsample of the FCM network, with plot centres not permanently marked). When a new soil inventory was launched (to be installed in Bavaria by 2006), problems in identifying former plot centres lead to the decision to move the grids (FCM and soil) onto a subsample $(8 \times 8 \mathrm{~km})$ of the NFI. The advantage is that all the three data series (soil, FCM, NFI) may be evaluated together; the disadvantage is that the 1983-2006 data series is going to be ceased (Bauer A, pers. comm.).

\section{Conclusion}

It was not the intention of this paper to "defend" the FCM against NFI: in the past I was critical enough to the FCM (see Ferretti 1997, Percy \& Ferretti 2004). Rather, I think that forest monitoring greatly needs harmonization - but does not need to waste data series. After having spend 25 years and several millions of Euros in FCM (Lorenz et al. 2009), collecting tree condition, soil, foliar and - recently - deadwood and biodiversity data; Working Group on Forest Biodiversity 2007) in these plots, one needs to think carefully before stopping this data series without a clear concept ahead. For example, what will happen under the "all-inone" option in case a given NFI will change its design at the next inventory cycle? Should it results into a new "harmonization round"? And how these "rounds" can be harmonized at European level? Unfortunately, signs in this direction already exist, and some countries have recently shifted their FCM on their NFI network. In Finland, for example, the FCM was installed on the basis of the $8^{\text {th }}$ NFI in $1985-1986$ (Cozzi et al. 2002 and background documents); then, NFI was re-designed and plots allocated to a new network; and recently FCM has moved to the plots of the new NFI (Lindgren, pers. comm.). A scenario of continuous shift in networks will be very unfortunate, as reporting obligations (e.g., MCPFE) requires data about changes of forests condition over time. Although one may question the actual value of tree condition data series, the available FCM dataset is a unique resource that needs to be improved and used, not to be abandoned. While any attempt in improving harmonization and integration within and between FCM and NFI is very much welcome, it would be somewhat ironical that harmonization efforts will result into the disruption of the most harmonized time series of forest condition data in Europe. Financial resources are now limited and one may question whether it is worthwhile keeping two separate networks when an "all-in-one" may be enough. I reply that costs involved are not very different: if annual FCM should be kept, annual costs will remain the same regardless the network used, and will be only slightly increased at each NFI cycle if the functional integration of networks will be promoted. For example, current FCM plots in Italy are about $3.5 \%$ of the mensurative ground plots of the NFI (INFC 2006); in Austria the proportion is $5 \%$ (national $\mathrm{FCM}$ ) or $1.25 \%$ (international FCM - Neumann 1993): this figure are expected to have a limited impact on the whole costs. In my understanding, the functional integration appears the most effective one among the three possible harmonization options presented in this paper: it is conservative (long-term data series is maintained), powerful (allow the integration of data and offer chances for more precise estimates), and relatively low-cost (double assessment on a limited number of plots only at NFI cycles).

Quoting Stout (1993), it is "ugly" that initial enthusiasm for monitoring programmes wanes and programmes are abandoned; and it is "bad" when monitoring programmes change protocols in midstream, leaving collections of incompatible data in their wake. In my opinion, before embarking into a process involving secure losses (data series and tax payers money spent to build them) $v s$. insecure gains, we need to carefully consider "the good, the bad and the ugly" for the monitoring of European forests.

\section{Acknowledgements}

I am grateful to Dr. Patrizia Gasparini and Dr. Lucio Di Cosmo (CRA-MPF, Trento, Italy) for the open discussion, and to Dr. Markus Neumann (BFW, Wien, Austria) for a number of stimulating comments on the manuscript. I am in debt also with Prof. Lorenzo Fattorini (University of Siena, Italy) for additional discussion on the topic. Dr. Arthur Bauer (LWF, Freising, Germany) provided a detailed explanation about the FCM and NFI processes in Bavaria (Germany).

\section{References}

Anonymous (1988). Forest damage and air pollution, report of the 1987 forest damage survey in europe. UN/ECE/UNEP, Geneva, pp. 55.

Anonymous (1994). Manual on methodologies and criteria for harmonized sampling, assessment, monitoring and analysis of the effects of air pollution on forests. PCCs, UN/ECE, Hamburg, Prague, Geneva, pp. 177.

Bussotti F, Cozzi A, Cenni E, Bettini D, Sarti C, Ferretti M (2009). Quality assurance and measurement errors in monitoring tree crown conditions in Italy. J. Environ. Monit. 11: 769. - doi: 10.1039/b818166g

Cozzi A, Ferretti M, Lorenz M (2002). Quality assurance for crown condition assessment in Europe. Final report. United Nation Economic Commission for Europe, Geneva, 111 p. Available from: Dr. Martin Lorenz, PCC ICP Forests, Hamburg, Germany. [online] URL: http://www. icp-forests.org 
Fattorini L, Marcheselli M, Pisani C (2006). A three-phase sampling strategy for large-scale multiresource forest inventories. Journal of Agricultural, Biological and Environmental Statistics 11: 296-316. - doi: 10.1198/108571106X130548 Ferretti M (2004). Forest health diagnosis, monitoring and evaluation. In: "Encyclopedia of forest sciences” (Burley J, Evans J, Youngquist J eds). Elsevier Science, London, pp. 285-299.

Ferretti M (1997). Forest health assessment and monitoring. Issues for consideration. Environmental Monitoring and Assessment 48: 45-72. doi: 10.1023/A:1005748702893

Ferretti M, König N, Rautio P, Sase H (2009). Quality assurance in international forest monitoring programmes: activity, problems and perspectives from East Asia and Europe. Annals of Forest Sciences 66: 403. - doi: 10.1051/ forest/2009025

Gasparini P, Bertani R, De Natale F, Di Cosmo L, Pompei E (2009). Quality control procedures in the Italian national forest inventory. Journal of Environmental Monitoring 11: 761-768. - doi: 10.1039/b818164k

INFC (2006). Procedure di posizionamento e di rilievo degli attributi di terza fase con istruzioni per l'impiego degli applicativi NAV3 e RAS3 (Tabacchi G, Scrinzi G, Tosi V, Floris A, Paletto A, Di Cosmo L, Colle G eds). MiPAF, CFS, CRA - ISAFA, Trento, Italy.

Innes JL (1993). Forest health: its assessment and status. Commonwealth agricultural bureau,
Wallingford, Connecticut, USA, pp. 677.

Innes JL, Landmann G, Mettendorf B (1993).

Consistency of observation of forest tree defoliation in three European countries. Environmental Monitoring and Assessment 25: 29-40. doi: 10.1007/BF00549790

Köhl M, Traub B, Päivinen R (2000). Harmonization and standardization in multi-national environmental statistics: mission impossible? Environmental Monitoring and Assessment 63: 361380 .

Lorenz M, Fischer R, Becher G, Iost S, Mues V, Granke O, Braslavskaya T, Bobrinsky A, Clarke $\mathrm{N}$, Lachmanová Z, Lukina $\mathrm{N}$, Schimming C (2009). Forest condition in Europe - 2009. Technical report of ICP forests, $2^{\text {nd }}$ draft. Work Report Institute for World Forestry, Hamburg, Germany, pp. 94.

MAF-ISAFA (1985). IFN - Inventario Forestale Nazionale. Sintesi metodologica e risultati. ISAFA-MAF, Trento, pp. $364+14$ cartography. Mc Roberts RE, Tomppo EO, Schadauer K, Vidal C, Stahl G, Chirici G, Lanz A, Cienciala E, Winter S, Smith WB (2009). Harmonizing national forest inventories, Journal of Forestry 107 (4): 179-187.

Moffat AJ, Davies S, Finér L (2008). Reporting the results of forest monitoring - an evaluation of the European forest monitoring programme. Forestry 81 (1): 75-90. - doi: 10.1093/forestry/ cpm046

Mues V (2006). Results of the international cross- comparison courses 2005. Programme Co-ordinating centre of ICP Forests, BFH, Hamburg, Germany, pp. 37.

Neumann M (1993). Forest damage assessments in Austria. Environmental Monitoring and Assessment 28: 183-188. - doi: 10.1007/ BF00547036

Olsen AR, Sedrransk J, Edwards D, Gotway CA, Ligget W, Rathbun S, Reckhow KH, Young LJ (1999). Statistical issues for monitoring ecological and natural resources in the United States, Environmental Monitoring and Assessment 54: 1-45. - doi: 10.1023/A:1005823911258

Percy K, Ferretti M (2004). Air pollution and forest health: Towards new monitoring concepts. Environmental Pollution 130: 113-126. - doi: 10.1016/j.envpol.2003.10.034

Stout BB (1993). The good, the bad and the ugly of monitoring programs: defining questions and establishing objectives. Environmental Monitoring and Assessment 26: 91-98. - doi: 10.1007/BF00547488

Winter S, Chirici G, Mc Roberts RE, Hauk E, Tomppo E (2008). Possibilities for harmonizing national forest inventory data for use in forest biodiversity assessments, Forestry 81 (1): 33-44. - doi: 10.1093/forestry/cpm042

Working Group on Forest Biodiversity (2007) The BioSoil forest biodiversity field manual version 1.0/1.1/1.1a for the field assessment 200607. Forest Focus demonstration project BioSoil 2004-2005, pp. 49. 